\title{
Applications of Soft Computing in Civil Engineering: A Review
}

\author{
Vinay Chandwani \\ Ph.D Research Scholar \\ Department of Civil Engineering \\ Malaviya National Institute of \\ Technology Jaipur, Rajasthan, \\ India
}

\author{
Vinay Agrawal \\ Assistant Professor \\ Department of Civil Engineering \\ Malaviya National Institute of \\ Technology Jaipur, Rajasthan, \\ India
}

\author{
Ravindra Nagar \\ Professor \\ Department of Civil Engineering \\ Malaviya National Institute of \\ Technology Jaipur, Rajasthan, \\ India
}

\begin{abstract}
The field of engineering is a creative one. The problems encountered in this field are generally unstructured and imprecise influenced by intuitions and past experiences of a designer. The conventional methods of computing relying on analytical or empirical relations become time consuming and labor intensive when posed with real life problems. To study, model and analyze such problems, approximate computer based Soft Computing techniques inspired by the reasoning, intuition, consciousness and wisdom possessed by a human beings are employed. In contrast to conventional computing techniques which rely on exact solutions, soft computing aims at exploiting given tolerance of imprecision, the trivial and uncertain nature of the problem to yield an approximate solution to a problem in quick time. Soft Computing being a multi-disciplinary field uses a variety of statistical, probabilistic and optimization tools which complement each other to produce its three main branches viz., Neural Networks, Genetic Algorithms and Fuzzy Logic. The review paper presents the applications of two major Soft Computing techniques viz., Artificial Neural Networks and Genetic Algorithms in the field of Civil Engineering, which to some extent has replaced the time consuming conventional techniques of computing with intelligent and time saving computing tools.
\end{abstract}

\section{Keywords}

Soft Computing, Artificial Neural Networks, Genetic Algorithms, Hybrid Soft Computing.

\section{INTRODUCTION}

Complexity to mathematically model real world problems has compelled the human civilization to search for nature inspired computing tools. The evolution of such computing tools revolves around the information processing characteristics of biological systems. In contrast to conventional computing, these tools are rather "soft" as they lack the exactness and therefore placed under the umbrella of a multidisciplinary field called soft computing. Soft Computing is an emerging collection of methodologies which aim to exploit tolerance for imprecision, uncertainty and partial truth to achieve robustness, tractability and total low cost [1]. It is a branch of computational intelligence research that employs a variety of statistical, probabilistic and optimization tools to learn from past examples and to then use that prior training to classify new data, identify new patterns or predict novel trends [2]. Soft Computing tools exploit the reasoning, intuition, consciousness, wisdom and adaptability to changing environments possessed by human beings for developing computing paradigms like Fuzzy Logic, Neural Networks and Genetic Algorithms. The integration of these techniques into the computing environment has given impetus to the development of intelligent and wiser machines possessing logical and intuitive information processing capabilities equivalent to human beings. These techniques whether complementing each other or working on their own, are able to model complex or unknown relationships which are either nonlinear or noisy. Soft computing techniques have a self adapting characteristic paving a way for development of automated design systems. A synergistic partnership exploiting the strengths of these individual techniques can be harnessed for developing hybrid computing tools.

Among the forerunners in the field of soft computing is the Artificial Neural Network (ANN). Inspired by the functioning of a human brain, they have immense potential in modeling functional relationships which either too complex or unknown in nature. ANN model is a system of interconnected computational neurons arranged in an organized fashion to carry out an extensive computing to perform a mathematical mapping [3]. Unlike conventional methods of computing which are based on predefined rules, ANNs work on vague functional relationships through a process of learning from experience and examples. Fuzzy Logic was conceptualized by Zadeh [4] in the year 1965. Inspired by how a human being makes decisions in dealing with knowledge that is inexact, imprecise and vague in nature; Fuzzy logic (FL) in a way emulates a human expertise in solving a particular problem. Genetic Algorithms (GAs) are stochastic search and optimization tools, which aim at finding the optimal solution to a problem which has many sub-optimal solutions. They require little information about the problem to be solved and can effectively work with complex constraints and discrete variables. GAs working on the operators of natural evolution viz., reproduction, crossover and mutation inspired by Darwin's principle of "Survival of the Fittest", are able to find the global optimal solution to a particular problem.

Civil Engineering is a diversified field ranging from waterresources to design and analysis of structures. The nature of the problems encountered in this field is of a complex nature and mostly requiring human intervention in the form of past experience and intuition. The heuristic nature of problems poses challenges to a civil engineer thereby making him resort to time and resources saving computational tools. Soft computing techniques viz., Neural Networks, Fuzzy Logic and Genetic Algorithms either working independently or complementing each other support the engineering activities by harnessing the cognitive behavior of the human mind to arrive at cost effective solutions. The review paper is an attempt to highlight the applications of Artificial Neural Networks and Genetic Algorithms in the field of Civil Engineering. 


\section{ARTIFICIAL NEURAL NETWORKS}

Artificial Neural Networks (ANNs) are computational models designed to mimic the learning abilities of a human brain. Haykin [5] described a neural network as a massively parallel distributed processor made up of simple processing units, which has a natural propensity for storing experiential knowledge and making it available for use. ANNs can be regarded as an engineering counterpart of a biological neuron. The interconnected processing units are called artificial neurons and replicate the functioning of biological neurons. Individually, the neurons perform trivial functions, but collectively, in the form of a network, they are capable of solving complicated problems [6]. ANNs rely on the past knowledge and when presented with input-output data pairs they construct a functional relationship through a process of learning. The learning ability of neural networks is attributed to the adjustment in the intensity of inter-neuron connection or the synaptic weight value. Adaptability to changing inputoutput data, non-linear function mapping and the ability to capture unknown relationships, makes ANNs a versatile tool for modeling the real world problems. The sub-sections elaborate the neural network applications in the field of Civil Engineering.

\subsection{Structural Engineering Applications}

Vanluchene and Sun [7] presented an introduction to neural network by using back-propagation algorithm to solve three different structural engineering problems related to pattern recognition, decision making and problems that have numerically complex solutions. Hajela and Berke [8] examined the role of neural computing in structural engineering by obtaining the optimum weight of a truss. Rogers [9] applied neural networks to structures having a large degree of freedom and showed that neural networks present computationally less expensive option compared to conventional structural analysis program. Mukherjee and Deshpande [10] developed neural network for initial design of reinforced-concrete rectangular single-span beams. The network predicts a good initial design (i.e., tensile reinforcement required, depth of the beam, width, cost per meter, and the moment capacity) for a given set of input parameters (i.e., span, dead load, live load, concrete grade, and steel type).

Adeli and Park [11] developed a neural dynamics model for optimum design of structures. Elazouni et al. [12] showed how neural networks can be used for estimating resource requirements at the conceptual stage of design. They showed that neural networks are versatile tools for analogy based solutions. Sanad and Saka [13] used ANN to predict the ultimate shear strength of reinforced concrete deep beams. The result of the ANN was compared with various empirical relationships and proved that ANNs provide a good prediction of shear strength. Hadi [14] developed neural network for optimum design of simply supported concrete beams and reinforced fibrous concrete beams and proved the effectiveness of ANNs compared to conventional design techniques. Oreta and Kawashima [15] explored the applications of ANN to predict the compressive strength and corresponding strain of circular concrete columns. ANN model has been developed to predict the shear strength of reinforced concrete beams without and with web reinforcement by Cladera and Mari [16] [17].

Cost optimization of single and multiple span reinforced concrete slabs with various end conditions subjected to all constraints has been presented by Ahmadkhanlou and Adeli [18]. Pendharkar et al. [19] presented a methodology using
ANN for predicting the inelastic moments considering instantaneous cracking and time effects for continuous composite beams. Erdem [20] investigated the application of neural networks for predicting the ultimate moment capacity of reinforced concrete (RC) slabs in fire. Bagci [21] analyzed the moment-curvature relationship of reinforced concrete governed by a large number of variables and non-linear material behavior using ANN. Jasim and Mohammed [22] used neural networks for predicting the ultimate torsional strength of spandrel beams. The results of resilient backpropagation algorithm training function were compared with a steepest descent algorithm. Jakubek [23] presented the application of neural networks in prediction of load capacity for eccentrically loaded reinforced concrete columns.

\subsection{Concrete Strength Modeling}

Yeh [24] proposed a method for optimizing high-performance concrete mix is proportioning for a given workability and compressive strength using ANN and non-linear programming. The methodology has been compared with experimental results from different mix proportions to prove its utility. Guang and Zong [25] used neural networks to predict 28-day compressive strength of concrete using multilayer feed-forward neural networks. Gupta et al. [26] attempted to use ANN for accurate prediction of concrete strength based on the parameters like concrete mix design, size and shape of the specimen, curing technique and period, environmental conditions, etc. Yeh [27] demonstrated the capability of ANN to model the slump of a highly complex material Fly ash and slag concrete (FSC). The model helped to explore the complex nonlinear relationships between concrete components and concrete slump.

Ozturan et al. [28] used ANN technique for predicting 28-day strength of ready mixed concretes having low to medium strength. The accuracy of ANN results was compared with that of multiple linear regression models and Abram's law. Alshihri et al. [29] used neural networks for predicting the compressive strength of structural lightweight concrete. The neural network was able to successfully predict the compressive strength after 3, 7, 14 and 28 days of curing. Aggarwal and Aggarwal [30] presented the comparative performance of models developed to predict 28-days compressive strengths using neural network techniques for data taken from literature and data developed experimentally for self compacting concrete containing bottom ash as partial replacement of the fine aggregates. The study showed that the model developed from the literature data can be easily extended to the experimental data, with bottom ash as partial replacement.

\subsection{Geotechnical Engineering Applications}

Shahin et al. [31] used neural networks for predicting settlement of shallow foundations on cohesionless soils. The predictive ability of ANN is compared with three of the most commonly used traditional methods. The prediction accuracy of ANN has been proved in this study. Young-Su and ByungTak [32] used backpropagation ANN model to predict the liquefaction cycle resistance ratio of sands using laboratory data. The neural network model was able to effectively capture the liquefaction resistance of a number of sands under varying initial conditions. Das et al. [33] studied the dynamic soil-pile interaction based on both experimental and numerical studies. Artificial neural network (ANN) models are developed based on field test results for the prediction of dynamic behavior of piles under coupled motion. Nath and Hazarika [34] used ANN to study the pile cap resistance under lateral load. The trained ANN model is able to effectively 
capture the phenomenon and can be used to study the influences of the different parameters on lateral resistance of pile cap.

\subsection{Water Resources Applications}

Most of the application of neural networks in the field of water resources engineering is centered on the rainfall-runoff modeling. Tokar and Johnson [35] used ANN to forecast daily runoff as a function of daily precipitation, temperature and snowmelt. The results were compared with statistical regression and a simple conceptual model, to prove that ANN provides a more systematic approach and reduces the time spent in calibration of the models. Wilby et al. [36] examined the internal behavior of an artificial neural network rainfallrunoff model. The output of the neural network model was studied to reveal that the hidden nodes in the neural network are associated with distinct 'quickflow' and 'baseflow' components. Jeong and Kim [37] used two types of ANNs, single neural network and ensemble neural network to provide better rainfall-runoff simulation capability than the existing models. Abrahart and See [38] examined the potential of ANN to perform the non-linear hydrological transformations under controlled conditions and showed that neural networks are appropriate tools for hydrological modeling. Golabi et al. [39] used ANN as a tool for modeling and predicting behavioral pattern in rainfall phenomenon based on past observations.

The other applications of ANN in the water resources sector include sediment modeling, evapo-transpiration modeling and irrigation scheduling. Nagy [40] used back-propagation artificial neural networks to estimate sediment load and compared the results with conventional formulas to prove its effectiveness. Cigizoglu [41] compared the ANNs and sediment rating curves for two rivers with very similar catchment areas and characteristics and highlighted the potential advantages of ANNs in sediment concentration and flux assessment. Rai and Mathur [42] developed ANN models for computation of event based temporal variation of sediment yields from the watersheds. Teng and Suetsugi [43] used ANN to predict the suspended load in ungauged catchments. Kumar et al. [44] studied the utility of ANN for estimation of daily grass reference evapotranspiration and compared the performance of ANN with the conventional method. Tabari et al. [45] compared the ANN models with multivariate nonlinear regression for estimating the pan evaporation. The study proved that ANN models provide the best estimates for pan evaporation. Karasekreter et al. [46] used ANN to propose a new system of irrigation ratios and time intervals and proved that irrigation at night could reduce losses from evaporation and thereby promoting water conservation.

\subsection{Earthquake Engineering Applications}

Lee and Han [47] developed efficient neural network models for generation of artificial earthquakes and response spectra. Cho et al. [48] developed neural network control for nonlinear bridge systems in earthquake excitation and assessed the robustness of the control system using randomly generated earthquake excitations. Ghaboussi and Elnashai [49] proposed neural network modeling of complex behavior of beamcolumn connection. ANN model was trained using self simulation to learn the cyclic behavior of the beam-column connection. Arslan [50] evaluated the effective design parameters and earthquake performance of the RC buildings using neural networks. The earthquake performance estimation percentages of the selects ANN algorithms vary between $91.68 \%$ and $98.47 \%$ depending on the type of the algorithm and other parameters of the ANN model. Xie et al.
[51] used the non-linear prediction ability and the generalization ability of ANN to create a model using the seismicity variation rate as the input and validated using the observed data. Robles and Becerril [52] used neural networks and genetic algorithms to create an alarming system for earthquakes greater than 4.5 on the Richter scale.

\section{GENETIC ALGORITHMS}

Problems faced in the field of engineering are multi-faceted, primarily involving evaluation of the optimal solution to a problem governed by a number of numerical constraints of complex nature. The level of difficulty to choose the best among the available alternatives, has compelled to detach from conventional techniques of analysis and move towards nature inspired computational tools which have features like reproduction and self adaptation to a changing environment. Genetic Algorithms (GAs) are a class of stochastic optimization technique, which work on the principle of evolution. According to Koza [53] "The genetic algorithm is a highly parallel mathematical algorithm that transforms a set (population of individual mathematical objectives typically fixed-length character strings patterned after chromosome strings), each with an associated fitness value, into a new population (i.e., the next generation) using operations patterned after the Darwinian principle of reproduction and survival of the fittest and after naturally occurring genetic operations (notably sexual recombination)".

The process of optimization lies at the root of engineering, since the classical function of the engineer is to design new, better, more efficient and less expensive systems as well as to devise plans and procedures for the improved operation of existing systems [54]. The application of GA in the field of Civil Engineering primarily deals with optimization problems governed by mixed nature of variables. This is in contrast to conventional optimization techniques which are based on steepest gradient descent approach and applicable to continuous nature of variables. This paradigm shift in the methodology to solve multi-objective problems influenced by sub-optimal solutions has created interest in the field of directed search algorithms which not only aim at feasible design but also caters to the requirements of the design objective. The following sections elaborate the applications of $\mathrm{GA}$ in the field of Civil Engineering.

\subsection{Structural Engineering Applications}

The applications of GA in the field of structural engineering deal with cost optimization of reinforced concrete and steel structures. Goldberg and Samtani [55] were the first to use GA for structural optimization by taking the example a 10-bar plane truss. Deb [56] applied GA to optimize the design of welded beam. Jenkins [57] used the GA to create an optimum design environment for plane frames. The study showed that this type of design environment is useful for parametric study and was extended to the design of the cable stayed bridge structure. Rajeev and Krishnamoorthy [58] used GA for discrete optimization of three bar truss and showed the utility of the GA technique in solving problems governed by discrete variables. Koumousis and Arsenis [59] used the GA technique for the optimal detailed design of reinforced concrete members of multi-storey buildings. The method decides the detailed design on the basis of a multi-criterion objective that represents a compromise between a minimum weight design, a maximum uniformity and the minimum number of bars for a group of members. Sarma and Adeli [60] presented the cost optimization of concrete structures which included beams, slabs, columns, frame structures, bridges, water tanks, folded plates, shear walls, pipes, and tensile members. Chau and 
Albermani [61] used GA for the design of liquid retaining structures having three discrete variables viz., slab thickness, reinforcement diameter and reinforcement spacing.

Camp et al. [62] presented a design procedure using GA for discrete optimization of reinforced concrete frames. The objective was to minimize the material and construction costs subjected to serviceability and strength requirements. The design procedure was further extended for the flexural design of simply supported beams, uniaxial columns and multi-storey frames. Fu et al. [63] used simple GA with elitism to find the optimum weight and cost of welded steel plate girder bridges having single span and two-equal continuous spans. Guerra and Kiousis [64] presented an optimization approach for design of reinforced concrete structures by optimizing the stiffness correlation among all structural members resulting in cost saving compared to typical practice design solutions. Senouci and Ansari [65] presented genetic algorithm based model for cost optimization of composite beams. The objective function is formulated by incorporating the major decision variables affecting the design of composite beams. The objective was to optimize the cost of composite beams. Alqedra et al. [66] used genetic algorithms to optimize the cost of prestressed and reinforced concrete beams. Aydin and Ayvaz [67] investigated the effective use of GA for overall cost optimization of prestressed concrete bridges to determine the optimum span number and the optimum cross-sectional properties of multi-span bridges.

\subsection{Concrete Mix Design Applications}

Noguchi et al. [68] characterized the proportioning of concrete mixture as multi-criteria optimization problem. The GA based technique derived appropriate mix proportions from vast combinations of content and proportions of the mixture. Amirjanov and Sobolev [69] used self adaptive GA with changing the mutation rate to concentrate the search for optimal selection and proportioning of concrete aggregates. Jayaram et al. [70] developed elitist GA models for the optimization of high volume fly ah concrete (HVFAC) mix. The proposed GA model was successful in reducing the number of trial mixtures with desired properties in the field tests. Xie et al. [71] used GA for optimizing the mix proportion design of high performance concrete satisfying the requirements of durability, strength, workability and dimensional stability of concrete. The results were compared with mix proportions in practice to establish the effectiveness of results obtained using GA. Rahman and Jumaat [72] used GA to derive a generalized formulation for determining the optimal quantity of materials used to produce non-slump concrete having minimum possible cost. The optimum formulation is based to meet compressive strength and workability requirements.

\subsection{Geotechnical Engineering Applications}

Cui and Sheng [73] proposed GA in finding the reliability index using finite element displacement method. The results of the GA were compared with other probability methods and it was found that GA was fairly quick in evaluating the failure performance of Geotechnical problems involving a large number of decision variables. Liu et al. [74] proposed automatic grouping genetic algorithm (AGGA) to optimize the pile design to minimize the cost of the foundation at the conceptual stage of design. The proposed methodology achieved the optimization of pile size, layout and grouping. Liu et al. [75] modeled the optimization of load-bearing capacity of composite foundation using GA. The regression analysis showed that the chosen model had good predicting accuracy and stability. Manouchehrian et al. [76] used GA for slope stability estimation. A regression model was developed using GA and was used for predicting the factor of safety. The study showed that the model was able to evaluate factor of safety at higher level of confidence.

\subsection{Water Resources Applications}

Nixon et al. [77] examined the use of GA to identify water delivery schedules for an open-channel irrigation system. The study showed the ability of GA techniques to maximize the number of orders to be delivered at the requested time along with minimizing the variation in the channel flow rate. Bhattacharjya [78] used GA to solve the nonlinear optimization problem to transmute a unit hydrograph into a probability distribution function. The objective was to minimize the sum of square of the deviation between predicted and direct runoff hydrograph of a watershed. Jain $e t$ al. [79] solved the nonlinear optimization program which allows spatial variations in velocity across a composite channel cross-section using GA. The objective was to minimize the total construction cost per unit length of a channel. The results show cost savings up to $35 \%$ for unconstrained velocity case and up to $55 \%$ for limiting velocity case. Cheng et al. [80] used GA to calibrate the conceptual rainfall-runoff model having 10 or more interdependent parameters. The current methodology showed considerable reduction in overall optimization time and improvement in the solution quality. Zhang et al. [81] used GA as search and optimization tool to optimize the sediment transport parameters viz., critical shear stress for deposition and resuspension.

\subsection{Earthquake Engineering Applications}

Sambridge and Gallagher [82] used GA to quickly locate the hypocenter of an earthquake by minimizing some misfit criteria of the data. Yu et al. [83] used GA to invert the parameters of an earthquake ruptured fault. The GA was able to find the global extreme and was found to be far more superior to other inverting schema in many respects. Naeim et al. [84] presented a new method for selection of earthquake ground motion that in combination match a given site specific design condition. GA quickly identified the optimum value of 14 variables and gave the least mean square of deviation from the target. Wongprasert and Symans [85] used GA to identify the optimal distribution of dampers to control the seismic response of a 20-story benchmark building. The study revealed that most of the dampers tend to be concentrated in the lowermost and uppermost stories.

Yilmaz [86] used GA to estimate the peak ground accelerations (PGA). For modeling PGA, magnitude, depth of foundation, epicentral distance, average shear wave velocity and slope height at the site were taken as the input parameters. The proposed model had good correlation between the measured and estimated PGA values. The model is also compared with local empirical predictive models and its results are found to be reasonable. Hejazi et al. [87] used GA to optimize the structural control systems to protect structures against severe earthquake excitation. The safety of the structure depends on many factors hence GA is used to optimize each of these parameters to minimize the effects of the earthquake.

\section{HYBRID ANN-GA APPLICATIONS}

The hybridization of Soft Computing techniques has provided the user with an alternative to use the best of the individual computing tools. The synergistic application of hybrid tools has opened up new avenues in the field of computing. A few hybrid ANN-GA applications are discussed here. Rao and 
Babu [88] used ANN and GA for the design of beams subjected to moment and shear. GA was used to optimize the neural network parameters thus reducing computational time and increasing predicting efficiency of ANN. Kim et al.[89] optimized the mixing proportion of recycled aggregate concrete (RAC) using ANN based on GA for increasing the use of recycled aggregate. The research revealed that the proposed method is proper for optimizing the mixing proportions of RAC. Nikoo et al. [90] used ANN to determine the displacement in concrete for a reinforced concrete building subjected to an earthquake. GA was applied to optimize the topology of ANN. Zhang and Wang [91] applied GA to optimize the ANN, thereby increasing its ability to locate the global minima. The hybrid neural network was used to predict the earthquakes.

$\mathrm{Fu}$ and Kapelan [92] investigated the use of ANN in combination with GA to improve the computational efficiency in solving the multi-objective water distribution system design problems. Results show that the method proposed can achieve a significant reduction in computation time, without loss in accuracy of the optimal solutions. Jain and Srinivasulu [93] used GA to train ANN for developing a model for lowmagnitude flows and proved that deterministic and ANN approaches perform better than purely ANN based models. Chen et al. [94] used stepwise optimization model for optimization the conjunctive use of surface and subsurface water resource management. The study proposed a hybrid approach consisting of GA, ANN and linear programming (LP). It was found that the proposed model has higher efficiency than other models with a purebred architecture or traditional groundwater numerical simulations. Adib and Jahanbakhshan [95] optimized the architecture of ANN using GA, to determine the suspended sediment concentration. The ANN model was calibrated using the observed data and regression relations were developed for locating the concentrations of suspended sediment.

\section{CONCLUSIONS}

Problems encountered in the real world are sometimes difficult to be solved analytically, or could be solved theoretically but actually impossible due to necessity of huge resources and/or enormous time required for computation. For these problems, computational tools inspired by nature sometimes work very efficiently and effectively. Although these tools do not provide exact answers to the problems, but are quite handy for problems governed by imprecise and vague data. These tools provide the user with sufficient decision making capabilities when dealing with uncertainty and vagueness. Such tools are classified under the umbrella of soft computing with the aim to build intelligent and wiser machines. Soft computing through the fusion of methodologies, supplement the conventional computational techniques with a human like behavior having the capabilities of reasoning, intuition, consciousness, wisdom and adaptability to changing environments.

Two important soft computing techniques viz., Artificial Neural Networks and Genetic Algorithms have been briefly described and their applications in the diversified field of Civil Engineering have been reviewed. The review shows that ANNs with the capability of harnessing the learning abilities resembling a human brain can be used to model complex nonlinear functional relationships without having to assume any prior functional relationship. The use of ANN in the field of Civil Engineering has made the complicated problems of modeling and prediction of behavior much easier. ANNs learning from historical data, capture the subtle functional relationships which surpassed most empirical and statistical methods already in practice in the field of engineering. The ANN addresses the problems whose solutions require prior knowledge which can be explicitly derived through historical data or experimental observations. Thus ANN can be used as a decision support tool for engineering problems whose solutions do not rely on a definite sets of rules or algorithms.

The stochastic search mechanism of GA inspired by natural evolution encourages an engineer to choose from a pool of multiple design alternatives. The operators of evolution viz., mutation, crossover and selection, refines the search and helps GA to bring forth the best design alternative satisfying the design objective. In the field of Civil Engineering, GA has been instrumental as an optimization tool dealing with discrete variables and arbitrary nature of constraints and objectives. The heuristic nature of GA provides improvement in the conventional design procedures aiding the development of economical and time saving design tools. The review paper has highlighted the use of GA as an optimization tool which explores and exploits the solution space and aims to find an optimal solution to a problem.

Hybridization of soft computing techniques has given a promising future to the development of next generation intelligent systems. The hybridization of GA and ANN discussed in the paper focuses on the complementing nature of the soft computing tools which encourages the user to derive the best from these techniques. Hybridization enriches the original procedures, covers up the limitations of individual techniques and helps the user resolve new problems. The conjunctive use of the techniques leads to accurate and robust solutions in comparison to those derived from an individual technique. Most of the applications of GA are centered on optimizing the neural network architecture and neural network weights during backpropagation learning. The result of ANNGA hybridization is very promising wherein the modeling capabilities of neural networks to derive complex functional relationships and the optimization capabilities of GAs are integrated to develop computational tools which can surely be a step beyond human cognitive skills.

\section{REFERENCES}

[1] Chaturvedi, D.K. 2008. Soft Computing Techniques and its applications in Electrical Engineering, Studies in Computational Intelligence, 103, 1-10.

[2] Mitchell, T. 1997. Machine Learning, McGraw Hill Education, India.

[3] Rafiq, M., Bugmann, G. and Easterbrook, D. 2001 Neural Network Design for Engineering Applications, Journal of Computers and structures, 79(17), 1541-1552.

[4] Zadeh, L.H. 1965. Fuzzy Sets, Information and Control, $8,338-353$.

[5] Haykin, S. 2009. Neural Networks A Comprehensive Foundation, $8^{\text {th }}$ Edn., Pearson Prentice Hall, India.

[6] Flood, I. and Kartam, N. 1994. Neural Networks in Civil Engineering. I: Principles and Understanding, Journal of Computing in Civil Engineering, 8(2), 131-148.

[7] Vanluchene, R.D. and Sun, R. 1990. Neural Networks in Structural Engineering, Computer-Aided Civil and Infrastructure Engineering, 5(3), 207-215.

[8] Hajela, P. and Berke, L. 1991. Neurobiological Computational Models in Structural Analysis and Design, Computers and Structures, 41(4), 657-667. 
[9] Rogers, J.L. 1994. Simulating Structural Analysis with Neural Network, Journal of Computing in Civil Engineering, 8(2), 252-265.

[10] Mukherjee, A. and Despande, J.M. 1995. Modeling Initial design process using Artificial Neural Networks, Journal of Computing in Civil Engineering, 9(3), 194200 .

[11] Adeli, H. and Park, H.S. 1995. A neural dynamics model for structural optimization-Theory, Computers and Structures, 57(3), 383-390.

[12] Elazouni, A.M., Nosair, I.A., Mohieldin, Y.A. and Mohamed. A.G. 1997. Estimating Resource Requirements at Conceptual Stage using Neural Networks, Journal of Computing in Civil Engineering, 11(4), 217-223.

[13] Sanad, A. and Saka, M. 2001. Prediction of Ultimate Shear Strength of Reinforced-Concrete Deep Beams Using Neural Networks, Journal of Structural Engineering, 127(7), 818-828.

[14] Hadi, M.N.S. 2003. Neural Network applications in Concrete Structures, Computers and Structures, 81(6), 373-381.

[15] Oreta, A.W.C. and Kawashima, K. 2003. Neural Network Modeling of Confined Compressive Strength and strain of Circular Concrete Columns, Journal of Structural Engineering, 129(4), 554-561.

[16] Cladera, A. and Mari, A.R. 2004. Shear design procedure for reinforced normal and high-strength concrete beams using artificial neural networks Part I: beams without stirrups, Engineering Structures, 26, 917-926.

[17] Cladera, A. and Mari, A.R. 2004. Shear design procedure for reinforced normal and high-strength concrete beams using artificial neural networks Part II: beams with stirrups, Engineering Structures, 26, 927-936.

[18] Ahmadkhanlou, F. and Adeli, H. 2005. Optimum cost design of reinforced concrete slabs using neural dynamics model, Engineering Applications of Artificial Intelligence, 18, 65-72.

[19] Pendharkar, U., Chaudhary, S. and Nagpal, A.K. 2007. Neural network for bending moment in continuous composite beams considering cracking and time effects in concrete, Engineering Structures, 29(9), 2069-2079.

[20] Erdem, H. 2010. Prediction of moment capacity of reinforced concrete slabs in fire using artificial neural networks, 41(2), 270-276

[21] Bagci, M. 2010. Neural Network Model for MomentCurvature relationship of Reinforced Concrete sections, Mathematical and Computational Applications, 15(1), 66-78.

[22] Jasim, N.A. and Mohammed, M.Y. 2011. Prediction of Ultimate Torsional Strength of Spandrel beams using Artificial Neural Networks, Basrah Journal for Engineering Science, 11(1), 88-100.

[23] Jakubek, M. 2012. Neural network prediction of load capacity for eccentrically loaded reinforced concrete columns, Computer Assisted Methods in Engineering and Science, 19, 339-349.
[24] Yeh, I. 1999. Design of High Performance Concrete Mixture using Neural Networks and Non-linear programming, Journal of Computing in Civil Engineering, 13(1), 36-42

[25] Guang, N.H. and Zong, W.J. 2000. Prediction of compressive strength of concrete by neural networks, Cement and Concrete Research, 30, 1245-1250.

[26] Gupta, R., Kewalramani, M. and Goel, A. 2006. Prediction of Concrete Strength using Neural-Expert System, Journal of Materials in Civil Engineering, 18(3), 462-466.

[27] Yeh, I. (2006). Exploring Concrete Slump Model Using Artificial Neural Networks, Journal of Computing in Civil Engineering, 20(3), 217-221.

[28] Ozturan, M., Birgul, K. and Ozturan, T. 2008 Comparison of Concrete Strength Prediction Techniques with Artificial Neural Network Approach, Building Research Journal, 56(1), 23-36.

[29] Alshihri, M.A., Azmy, A.M. and El-Bisy, M.S. 2009. Neural networks for predicting compressive strength of structural light weight concrete, Construction and Building Materials, 23, 2214-2219.

[30] Aggarwal, Y. and Aggarwal, P. 2011. Prediction of Compressive Strength of SCC containing Bottom Ash using Artificial Neural Networks, World Academy of Science, Engineering and Technology, 53, 735-740.

[31] Shahin, M.A., Maier, H.R. and Jaksa, M.B. 2002. Predicting settlement of Shallow Foundations using Neural Networks, Journal of Geotechnical and Geoenvironmental Engineering, 128(9), 785-793.

[32] Young-Su, K. and Byung-Tak, K. 2006. Use of Artificial Neural Networks in the Prediction of Liquefaction Resistance of Sands, Journal of Geotechnical and Geoenvironmental Engineering, 132(11), 1502-1504.

[33] Das, S., Manna, B. and Baidya, D.K. 2011. Prediction of Dynamic Soil-Pile Interaction under coupled vibration using Artificial Neural Network Approach, Geo Frontiers, 1-10.

[34] Nath, U.K. and Hazarika, P.J. 2011. Study of Pile Cap Lateral resistance using Artificial Neural Networks, International Journal Of Computer Applications, 21(1), 20-25.

[35] Tokar, S.A. and Johnson, P.A. 1999. Rainfall-Runoff modeling using Artificial Neural Networks, 4(3), 232239.

[36] Wilby, R.L. Abrahart, R.J. and Dawson, C.W. 2003. Detection of conceptual model rainfall-runoff processes inside an artificial neural network, Hydrological Sciences Journal, 48(2), 163-181.

[37] Jeong, D. and Kim, Y. 2005. Rainfall-runoff models using artificial neural networks for ensemble streamflow prediction, Hydrological Processes, 19, 3819-3835.

[38] Abrahart, R.J. and See, L.M. 2007. Neural network modeling of non-linear hydrological relationships, Hydrology and Earth System Sciences, 11, 1563-1579.

[39] Golabi, M., Radmanesh, F., Akhondali, A. and Kashefipoor, M. 2013. Prediction of Seasonal Precipitation using Artificial Neural Networks (Case 
Study: Selected Stations of (Iran) Khozestan Province), Journal of Basic and Applied Scientific Research, 3(1), 589-595.

[40] Nagy, H., Watanabe, K., and Hirano, M. 2002. Prediction of Sediment Load Concentration in Rivers using Artificial Neural Network Model.” Journal Hydraulic Engineering, 128(6), 588-595.

[41] Cigizoglu, H.K. 2002. Suspended sediment estimation for rivers using Artificial Neural Networks and sediment rating curves, Turkish Journal of Engineering and Environmental Sciences, 26, 27-36.

[42] Rai, R.K. and Mathur, B.S. 2008. Event based sediment yield modeling using Artificial Neural Networks, 22(4), 423-441.

[43] Heng, S. and Suetsugi, T. 2013. Using Artificial Neural Networks to estimate sediment in ungauged catchment of the Tonle Sap River Basin Cambodia, Journal of Water Resources and Protection, 5, 111-123.

[44] Kumar, M., Raghuwanshi, N., Singh, R., Wallender, W., and Pruitt, W. 2002. Estimating Evapotranspiration using Artificial Neural Network, Journal of Irrigation and Drainage Engineering, 128(4), 224-233.

[45] Tabari, H., Marofi, S. and Sabziparvar, A. 2010. Estimation of daily pan evaporation using artificial neural networks and multivariate non-linear regression, 28(5), 399-406.

[46] Karasekreter, N., Basciftci, F. and Fidan, U. 2013. A new suggestion for an irrigation schedule with an artificial neural network, Journal of Experimental and Theoretical Artificial Intelligence, 25(1), 93-104.

[47] Lee, S.C. and Han, S.W. 2002. Neural network based models for generating artificial earthquakes and response spectra, Computers and Structures, 80(20-21), 16271638.

[48] Cho, H.C., Fadali, M.S., Saiidi, S.M. and Soon, L.K. 2005. Neural network active control of structures with earthquake excitation, International Journal of Control, Automation and Systems, 3(2), 202-210.

[49] Ghaboussi, J. and Elnashai, A.S. 2007. Development of neural network based hysteretic models for steel beamcolumn connections through self learning simulation, Journal of Earthquake Engineering, 11, 453-467.

[50] Arslan, H.M. 2010. An evaluation of effective design parameters on the earthquake performance of RC buildings using neural networks, Engineering Structures, $32,1888-1898$

[51] Xie, J., Qiu, J., Wei, L. and Wang, J.W. 2011. The application of neural network in earthquake prediction in East China, Advances in Intelligent and Soft Computing, $106,79-84$

[52] Robles, C.M.A. and Becerril, H.R.A. 2012. Seismic alert system based on artificial neural networks, World Academy of science, Engineering and Technology, 66, 813-818.

[53] Koza, J. R. 1992. Genetic programming: On the Programming of Computers by Means of Natural Selection, MIT press.
[54] Ravindran, A., Ragsdell, K.M. and Reklaitis, G.V. 2006. Engineering Optimization: Methods and Applications, John Wiley \& Sons Inc, Hoboken, New Jersey, USA.

[55] Goldberg, D.E. and Samtani, M.P. 1986, Engineering optimization via genetic algorithm, Proceedings $9^{\text {th }}$ Conference on Electronic Computation, ASCE, 471-482.

[56] Deb, Kalyanmoy. 1991. Optimal design of a welded beam via genetic algorithms, AIAA Journal, 29, 20132015.

[57] Jenkins, W. 1992. Plane Frame Optimum Design Environment Based on Genetic Algorithm, Journal of Structural Engineering, 118(11), 3103-3112.

[58] Rajeev, S. and Krishnamoorthy, C. 1992. Discrete Optimization of Structures Using Genetic Algorithms, Journal of Structural Engineering, 118(5), $1233-1250$

[59] Koumousis, V.K., and Arsenis, S.J. 1994. Genetic algorithms in a multi-criterion optimal detailing of reinforced concrete members, Advances in structural optimization, CIVIL-COMP Ltd, Edinburgh, Scotland, 233-240.

[60] Sarma, K. and Adeli, H. 1998. Cost Optimization of Concrete Structures. Journal of Structural Engineering, 124(5), 570-578.

[61] Chau, K.W. and Albermani, F. 2002. Genetic Algorithms for design of Liquid Retaining Structures, Lecture Notes in Artificial Intelligence, 2358, 119-128.

[62] Camp, C., Pezeshk, S., and Hansson, H. 2003. Flexural Design of Reinforced Concrete Frames Using a Genetic Algorithm, Journal of Structural Engineering, 129(1), 105-115.

[63] Fu, K., Zhai, Y., and Zhou, S. 2005. Optimum Design of Welded Steel Plate Girder Bridges Using a Genetic Algorithm with Elitism, Journal of Bridge Engineering, 10(3), 291-301.

[64] Guerra, A., and Kiousis, D.P. 2006. Design optimization of reinforced concrete structures, Computers and Concrete, 3(5), 313-334

[65] Senouci, B.A., and Al-Ansari, S.M. 2009. Cost optimization of composite beams using genetic algorithms, Advances in Engineering Software, 40, 1112-1118

[66] Alqedra, M., Arafa, M., and Ismail, M. 2011. Optimum cost of Prestressed and Reinforced Concrete Beams using Genetic Algorithms, Journal of Artificial Intelligence, 4(1), 76-88.

[67] Aydin, Z. and Ayvaz, Y. 2013. Overall cost optimization of Prestressed concrete bridges using Genetic Algorithm, KSCE Journal of Civil Engineering, 17(4), 769-776.

[68] Noguchi, T. and Maruyama, I. 2003. Performance based design system for concrete with Multi-optimizing Genetic Algorithm, Proceedings of $11^{\text {th }}$ International Congress on Chemistry of Cement, Durban, South Africa.

[69] Amirjanov, A. and Sobolev, K. 2005. Optimal proportioning of concrete aggregates using a self adaptive genetic algorithm, Computers and Concrete, 2(5), 1-11. 
[70] Jayaram, M. A., Nataraja, M.C. and Ravikumar, C.N. 2009. Elitist Genetic Algorithm Models:Optimization of High Performance Concrete Mixes, Materials and Manufacturing Processes, 24(2), 225-229.

[71] Xie, X., Yan, D. and Zheng, Y. 2011. Optimization Design of High Performance concrete based on Genetic algorithm toolbox of Matlab, Advanced Materials Research, 250-253, 2672-2677.

[72] Rahman, M.M. and Jumaat, M.Z. 2012. Cost minimum proportioning of Non-Slump concrete mix using Genetic Algorithms, Advanced Materials Research, 468-471, 5054.

[73] Cui, L. and Sheng, D. 2005. Genetic Algorithms in probabilistic finite element analysis of geotechnical problems, Computers and Geotechnics, 32, 555-563.

[74] Liu, M., Qie, Z., Wu, X., Dong, W. and Zheng, H. 2008. Model optimization of load-bearing capacity of macadam pile composite foundation based on Genetic Algorithms, IEEE Control and Decision Conference, Yantai, 39033907.

[75] Liu, X., Cheng, G., Wang, B. and Lin, S. 2012. Optimum Design of Pile Foundation by Automatic Grouping Genetic Algorithms, ISRN Civil Engineering, 2012.

[76] Manouchehrian, A., Gholamnejad and Sharifzadeh, M. 2013. Development of a model for analysis of slope stability of circular mode failure using genetic algorithms, Environmental and Earth Sciences.

[77] Nixon, J.B, Dandy, G.C. and Simpson, A.R. 2001. A genetic algorithm for optimizing off-farm irrigation scheduling, Journal of Hydroinformatics, 3(1), 11-22.

[78] Bhattacharjya, R. 2004. Optimal design of unit hydrographs using probability distributions and genetic algorithms, Sadhana, 29(5), 499-508.

[79] Jain, A., Bhattacharjya, R. and Sanaga, S. 2004. Optimal design of composite channels using genetic algorithms, Journal of Irrigation and Drainage, 130(4), 286-295.

[80] Cheng, C., Wu, X. and Chau, K.W. 2005. Multiple criteria rainfall-runoff model calibration using a parallel genetic algorithm in a cluster of computers, Hydrological Sciences Journal, 50(6), 1069-1087.

[81] Zhang, F.X., Wai, O.W.H. and Jiang, Y.W. 2010. Prediction of sediment transportation in Deep Bay (Hong Kong) using Genetic Algorithms, Journal of Hydrodynamics Ser. B, 22(5), Supplement 1, 599-604.

[82] Sambridge, M. and Gallagher, K. 1993. Earthquake hypocenter location using Genetic Algorithms, Bulletin of the Seismological Society of America, 83(5), 14671491.

[83] Yu, T., Frenandez, J. and Rundle, J.B.1998. Inverting the parameters of an earthquake rupture fault with a genetic algorithm, Computers and Geosciences, 24(2), 173-182.
[84] Naeim, F., Alimoradi, A. and Pezeshk, S.2004. Selection and Scaling of Ground motion Time Histories for Structural Design using Genetic Algorithms, Earthquake Spectra, 20(2), 413-426.

[85] Wongprasert, N. and Symans, M. 2004. Application of a Genetic Algorithm for Optimal Damper Distribution within the Nonlinear Seismic Benchmark Building. Journal of Engineering Mechanics, 130, 401406.

[86] Yilmaz, S. 2011. Ground motion predictive modeling based on genetic algorithms, Natual Hazards and Earth System Sciences, 11, 2781-2789.

[87] Hejazi, F., Toloue, I. Jaafar, M.S. and Noorzaei, J. 2013. Optimization of Earthquake Energy Dissipation System by Genetic Algorithms, Computer Aided Civil and Infrastructure Engineering, 28(10), 796-810.

[88] Rao, H.S. and Babu, B.R.2007. Hybrid neural network model for the design of beam subjected to bending and shear, Sadhana, 32(5), 577-586.

[89] Kim, S., Choi, H.B., Shin, Y., Kin, G.H. and Seo, D.S 2013. Optimizing the mixing proportions with neural networks based on genetic algorithms for recycled aggregate concrete, Advances in Material Sciences and Engineering, 2013.

[90] Nikoo, M., Zarfam, P. and Nokoo, M. 2012. Determining the displacement in concrete reinforcement building using evolutionary artificial neural networks, World Applied Sciences Journal, 16(2), 1699-1708.

[91] Zhang, Q. and Wang, C. 2008. Using genetic algorithm to optimize artificial neural networks: A case study on Earthquake prediction, IEEE Second International Conference on Genetic and Evolutionary Computing, Hubei, 128-131

[92] Fu, G. and Kapelan, Z. 2011. Embedding Neural Networks in Multiobjective Genetic Algorithms for Water Distribution System Design, Water Distribution Systems Analysis 2010, 888-898.

[93] Jain, A. and Srinivasulu, S. 2004. Development of effective and efficient rainfall-runoff models using integration of deterministic, real coded genetic algorithms and artificial neural networks, Water Resources Research, 40(4).

[94] Chen, Y.W., Cheng, L.C., Huang, C.W. and Chu, H.J. 2013. Applying genetic algorithms and neural networks to the conjunctive use of surface and subsurface water, Water Resources Management 2013.

[95] Adib, A. and Jahanbakhshan, H. 2013. Stochastic approach to determination of suspended sediment concentration in tidal rivers by artificial neural networks and genetic algorithms, Canadian Journal of Civil Engineering, 40(4), 299-312. 